\title{
Estudos raciais na educação escolar com enfoque na branquitude brasileira: das margens para o centro
}

\section{Racial studies in school education with a focus on brazilian whiteness: from the margins to the center}

\author{
Andrelize Schabo Ferreira de Assis ${ }^{1 *}$, Kátia Sebastiana Carvalho dos Santos Farias ${ }^{2}$
}

\begin{abstract}
RESUMO
O objetivo deste artigo é contribuir com os estudos raciais ao problematizar a discussão sobre a branquitude brasileira, deslocando o olhar das margens para o centro (do oprimido para o opressor, da negritude para a branquitude) com base na interculturalidade crítica. A partir da pesquisa bibliográfica, discutiremos a teoria do branqueamento como um dos processos históricos que determinaram socioculturalmente as relações raciais no país; a branquitude brasileira como possibilidade de foco dos estudos raciais; e, por fim, a interculturalidade como estratégia e meta para abordar a temática da branquitude em sala de aula, dialogando com autores como Cardoso (2010); Walsh (2009); Freire (1967) e outros. Os estudos sobre a branquitude são relativamente recentes no país e têm o objetivo de preencher lacunas deixadas nos estudos raciais brasileiros, desconstruindo o "padrão branco" e suas consequências desumanizantes. Com base neste estudo, compreendemos que discutir na escola a branquitude brasileira e seus efeitos pode contribuir para enriquecer o debate racial, além de questionar e desconstruir a história branca, masculina, eurocêntrica e dominadora que fundou o Brasil e resultou nas desigualdades contra as quais lutamos.
\end{abstract}

Palavras-chave: Teoria do Branqueamento; Branquitude; Interculturalidade; Educação Escolar.

\begin{abstract}
The purpose of this article is to contribute to racial studies by problematizing the discussion on Brazilian whiteness, shifting the gaze from the margins to the center (from the oppressed to the oppressor, from blackness to whiteness) based on critical interculturality. In this sense, based on the bibliographical research, we will discuss the theory of whitening as one of the historical processes that socioculturally determined racial relations in the country; Brazilian whiteness as a possibility of focus on racial studies; and, finally, interculturality as a strategy and goal to address the theme of whiteness in the classroom, dialoguing with authors such as Cardoso (2010); Walsh (2009); Freire (1967) and others. Studies on whiteness are relatively recent in the country and aim to fill gaps left in Brazilian racial studies, deconstructing the "white pattern" and its dehumanizing consequences. Based on the study carried out, we understand that discussing Brazilian whiteness and its effects at school can contribute to enrich the racial debate, in addition to questioning and deconstructing the white, male, Eurocentric and dominating history that founded Brazil and resulted in the inequalities against which we fight.
\end{abstract}

Keywords: Whitening Theory; Whiteness; Interculturality; School Education.

\footnotetext{
${ }^{1}$ Instituto Federal de Educação, Ciência e Tecnologia de Rondônia (IFRO). *E-mail: andrelizeschabo@gmail.com

${ }^{2}$ Universidade Federal de Rondônia (UNIR).
} 


\section{INTRODUÇÃO}

Este artigo articula conteúdos estudados na disciplina Educação Escolar: História, Organização, Diferenças e Interculturalidades, em um Programa de PósGraduação de uma Universidade Federal localizada no Norte do Brasil, no ano de 2021. O objetivo é contribuir com os estudos raciais ao problematizar a discussão sobre a branquitude brasileira, deslocando o olhar das margens para o centro (do oprimido para o opressor, da negritude para a branquitude) com base na interculturalidade crítica.

Tendo em vista esse objetivo, a pesquisa bibliográfica foi desenvolvida por meio da leitura exploratória do recorte bibliográfico de autores selecionados com base nos textos apresentados na ementa da disciplina e no levantamento sobre o estado atual dos estudos e reflexões sobre a temática. Entre os diversos autores com produção científica disponível na área até o presente momento, optamos por dialogar com Cardoso (2010); Candau (2005); Walsh (2009); Schwarcz (2011); Freire (1967), entre outros, considerados pelas autoras importantes para o desenvolvimento da discussão proposta.

Inicialmente, em Política do Branqueamento e seus Efeitos na Sociedade Brasileira, faremos um breve resgate histórico sobre a teoria do branqueamento, pois, como afirma Candau (2008, p. 17), o debate multicultural nos coloca em frente aos processos históricos que determinaram socioculturalmente o que será valorizado ou desvalorizado, o que será afirmado ou negado dentro da cultura hegemônica. Assim, abordaremos a política do branqueamento na sociedade brasileira, com o objetivo de refletir sobre as estratégias de opressão dos povos não brancos elaboradas pelos brancos dominantes antes mesmo da restrição no tráfico de escravizados ou da abolição da escravatura, mas que se perpetuou no pós-abolição. Sabemos que o movimento de abolição no Brasil foi formal, devido a pressões internacionais e internas, mas a branquitude construiu e organizou estratégias para permanecer no poder e manter seus privilégios historicamente conhecidos.

Em Branquitude em Foco: um Estudo a Partir do Opressor, abordaremos a questão do enfoque dos estudos raciais no Brasil, em sua maioria, ser sobre a negritude no país e questões como racismo, antirracismo, cotas raciais e cotas sociais, políticas públicas, entre outras, a partir desse ponto de partida. Esses estudos são extremamente importantes e relevantes, porém deixam uma lacuna com relação aos estudos raciais sobre a branquitude brasileira, suas estratégias de dominação e de permanência dos privilégios. 
Por último, no item Diálogos Sobre Interculturalidades e Branquitudes, discutiremos as diferentes compreensões dos estudos multiculturais, branquitudes e branquidade, e, por fim, a interculturalidade como uma possibilidade e meta para abordar a temática da branquitude em sala de aula, retirando-a de sua pretensa "ausência de problema" (como se o racismo fosse problema apenas do negro). Nosso intuito é pontuar que apesar das diversas teorias e estratégias para tratar a temática em sala de aula, precisamos convergir em deslocar o olhar também para o foco do problema da hierarquização das raças no Brasil: a branquitude.

\section{POLÍTICA DO BRANQUEAMENTO E SEUS EFEITOS NA SOCIEDADE BRASILEIRA}

Em verdade, o que caracterizou, desde o início, a nossa formação, foi, sem dúvida, o poder exacerbado. (FREIRE, 1967, p. 74).

As diferenças culturais no Brasil e no mundo ainda hoje provocam tensões, reações de discriminação e intolerância, além de interpretações equivocadas por parte de grupos que insistem em uma homogeneização e/ou hierarquização das raças. Desde o início do século XIX, já se mostrava forte a ligação que se estabelecia entre educação e construção da ordem social. Neste período de consolidação dos Estados nacionais, a escola deveria ser vista como uma das instituições capazes de garantir a uniformidade nacional por meio da transmissão não só de um conteúdo unificado, mas também de valores culturais e morais que garantiriam a unidade nacional. Entendemos, assim, que a instituição escola foi projetada para garantir a uniformidade nacional por meio da transmissão não só de um conteúdo unificado, mas também, de valores culturais e morais que garantiriam a unidade nacional (FARIAS, 2014).

Como nos mostra Jacques Derrida, em entrevista concedida a Mustapha, a pluralidade, a alteridade, o princípio das diferenças e o respeito pela alteridade estão nos princípios da civilização e não é possível conceber "[...] uma civilização universal homogênea, seria o contrário de uma civilização" (MUSTAPHA, 2013, p. 86). No entanto, ideias assim circulavam pelo Brasil até pouco tempo, trazendo reflexos à composição da sociedade atual.

A história aponta que o determinismo biológico (darwinismo social) foi considerado a base do pensamento científico do século XIX com relação aos estudos raciais, classificando e hierarquizando os seres humanos para legitimar processos de 
dominação econômica e política. Nesse sentido, analisando a história de construção da identidade da sociedade brasileira, observamos que houve um projeto político eugenista instaurado no início do século XX no Brasil, voltado ao branqueamento da população. Na época, era comum nos meios oficiais a representação negativa da cultura da população negra, que sofria no processo pós-abolicionista por não ter oportunidades de inserção na sociedade.

\begin{abstract}
A política de branqueamento não é a única iniciativa de Estado responsável pelos efeitos do racismo na população; porém, sua permanência ainda é produtora de sofrimento psíquico e social. $\mathrm{O}$ conjunto das instituições republicanas, como o judiciário, o sistema educacional, as leis e as políticas públicas, entre outras, são uma rede tecida nas bases do racismo científico. A política do "embranquecimento" é parte dessa rede, constituindo-se e capilarizando-se nos planos mais sutis, micropolíticos, da história brasileira. (MAIA, 2018, p. 280).
\end{abstract}

Essas redes de ideias ecoaram também internacionalmente. Em 1911, no Congresso Universal de Raças $^{3}$, que contou com a presença de dois representantes do Brasil, João Baptista de Lacerda e Edgard Roquette-Pinto, observamos que o "esforço da política internacional brasileira no início do século XX consistia em vender uma imagem positiva sobre o país, visando atrair imigrantes e investimentos estrangeiros" (SOUZA, 2012, p. 754). Destacamos ainda que "o Brasil servia como um exemplo do cruzamento extremado de raças, algo que, no período, era visto como extremamente negativo" (SCHWARCZ, 2011, p. 226). Assim, buscando passar uma imagem positiva do país, foi apresentado por Lacerda um trabalho acerca da miscigenação racial no Brasil e do processo de branqueamento da população mestiça. Em acordo com as autoridades brasileiras e buscando promover o país na Europa, o autor afirma que em menos de um século ocorreria o branqueamento da população brasileira, pois "o negro passaria a branco, na terceira geração, por efeito do cruzamento de raças” (LACERDA, 1911).

\footnotetext{
${ }^{3}$ O congresso ocorreu em Londres, em 1911, e reuniu representantes e autoridades de mais de 50 países da Europa, América do Sul, América do Norte, Ásia e África. O objetivo do encontro, segundo seu próprio folheto, era "discutir, à luz da ciência e da consciência moderna, as relações gerais existentes entre os povos do Ocidente e do Oriente, entre os assim chamados brancos e os povos de cor, com a intenção de encorajálos a um amplo entendimento, com os mais amigáveis sentimentos e a mais saudável cooperação" (SPILLER, 1911, p. 13). No entanto, sabe-se que o intuito era discutir a sobrevivência do sistema colonialista e o controle dos conflitos raciais. Como afirma Souza (2012, p. 749), "o interesse do congresso dizia respeito, na verdade, às relações dos países imperialistas com os povos de regiões oficialmente colonizadas por europeus".
} 
A tela de Modesto Brocos ilustrou o trabalho de Lacerda e apresenta o que os teóricos do branqueamento projetavam para o futuro do Brasil. Schwarcz (2011, p. 227) mostra que a ideia defendida era a de que a mestiçagem brasileira seria transitória e não deixaria rastros na população brasileira após três gerações, resultando, assim como registrado na tela com a criança, em uma nova geração branca. "A seleção darwinista levaria, inicialmente, a uma população mestiça, que passaria a branca no porvir, e este seria o destino certo do Brasil"' (SCHWARCZ, 2011, p. 228). O texto de Lacerda enfatiza que em três gerações o país ofereceria um exemplo ao mundo, uma "redenção étnica", pois a população negra e indígena desapareceria entre os brasileiros. Apesar do caráter pretensamente "otimista" do trabalho apresentado por Lacerda, as ideias foram vistas com pessimismo internacionalmente, pois entenderam que três gerações seria muito tempo.

Figura 1 - “A Redenção de Can” (1895) - Autoria: Modesto Brocos y Gómes.

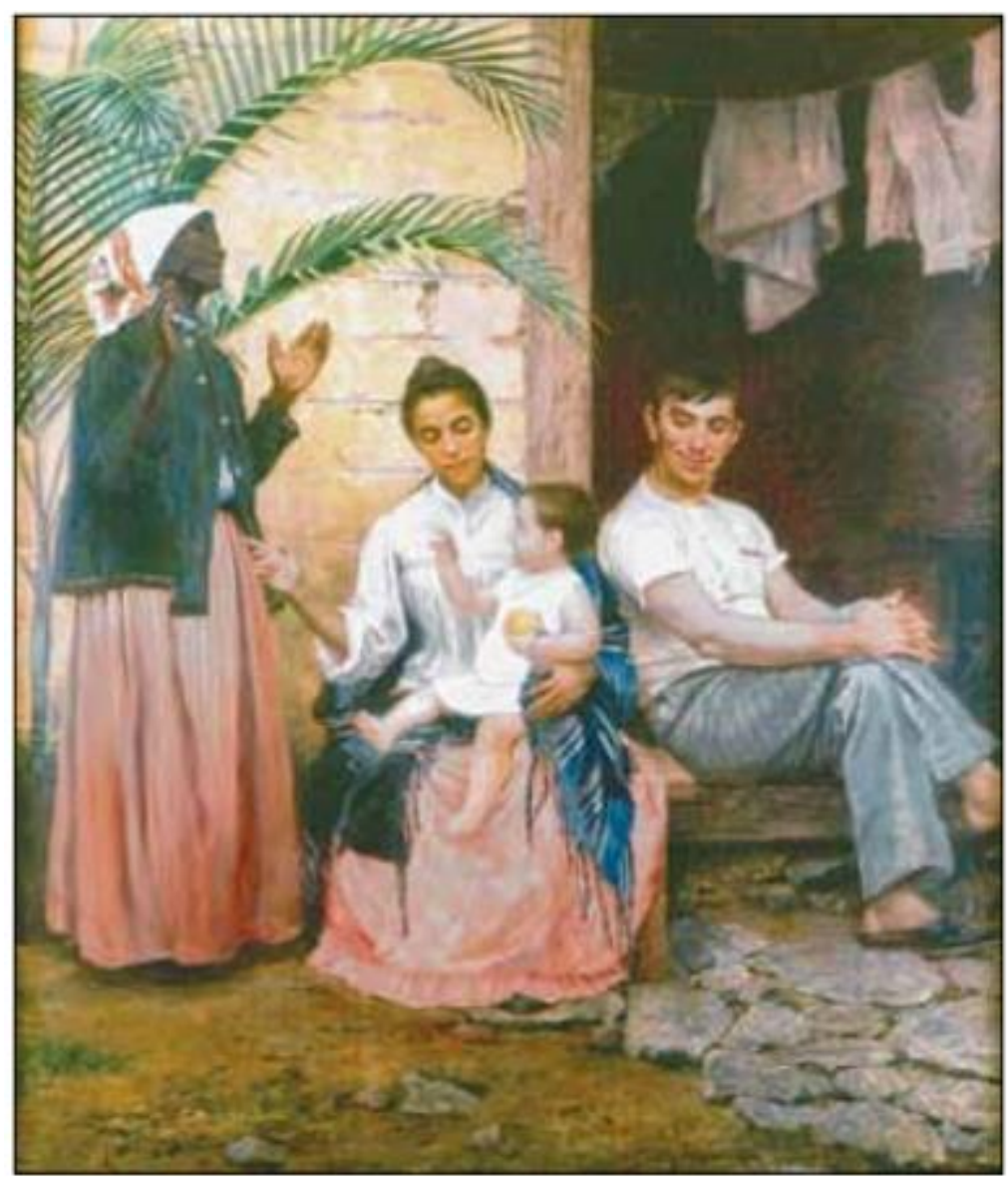

Fonte: Souza (2012, p. 755).

O intuito de mobilizar essas ideias em nosso estudo é tentar compreender as consequências deixadas pela utilização dessas teorias no Brasil, que se apresentam com 
diversas configurações e roupagens ao longo da história e ainda trazem reflexos à sociedade atual. Teorias do branqueamento começaram a tomar força no país, visando este suposto futuro "branco e civilizado". Desde ideias de limitar eugenicamente os casamentos, até incentivar a imigração de brancos em detrimento de outros grupos, tudo isso construiu o Brasil que se apresenta na atualidade. Apesar de tentar vender a ideia internacionalmente de que esse branqueamento incentivado seria pacífico e democrático, lembremos que também foi essa a ideia vendida sobre a escravidão no país. No entanto, dados estatísticos mostram que o país é violento, desigual e carrega a triste marca de ser um dos últimos a abolir a escravidão.

Destacamos que conceito de raça foi política e historicamente construído (é ficcional) e houve todo um investimento político e econômico nesses modelos biológicos de análise para justificar atrocidades cometidas em busca de desenvolvimento econômico (escravização e subjugação dos povos) ${ }^{4}$. O discurso do Lacerda carregava intenções políticas e suas graves consequências apresentam-se na configuração das desigualdades brasileiras na atualidade, pois, a partir daí, haverá o incentivo à imigração branca e nenhuma ação em benefício de populações não brancas. Além disso, Segundo Schucman (2012, p. 20), "no caso dos negros, a consequência seria uma não aceitação da sua autoimagem, da sua cor, o que resultaria em um 'pacto' com a ideologia do branqueamento", constituindo o que Frantz Fanon (1980) intitula sua obra Pele Negra, Máscaras Brancas. Portanto, tornar o branco o "padrão" a partir do qual todos os "outros" diferem-se não é algo natural, não há quaisquer justificativas biológicas para isso, foi (ou ainda é?) um projeto político e econômico que reflete na configuração da sociedade brasileira. Nesse sentido,

A resistência negra atual luta por reverter esses efeitos, produzindo algo talvez inédito na história da luta contra o racismo, afirmando a cultura e a ancestralidade negra e rompendo com o embranquecimento. É importante compreender os efeitos desse processo na subjetivação contemporânea. A coloridade, tonalidade e diferenças sociais podem ser ainda correlatas da política do embranquecimento, estabelecendo um dégradé de privilégios e exclusões. É real que um negro de tom de pele mais claro possa ter mais acesso aos espaços sociais, à saúde, às

\footnotetext{
${ }^{4}$ Assim, como afirma Walsh (2009, p. 16), "A matriz da colonialidade afirma o lugar central da raça, do racismo e da racialização como elementos constitutivos e fundantes das relações de dominação".

${ }^{5}$ A visão intercultural mostra que as diferenças são constituídas a partir de pontos de vista, em oposição a algo (alto x baixo; gordo x magro etc), não sendo fixas e imutáveis e não havendo melhor ou pior entre as diferentes culturas. Assim, compreender o branco como padrão fixo levou à discriminação e subjugação dos "outros", considerados fora da norma e que precisariam ser aniquilados.
} 
"irmandades" e aos vínculos sociais que pessoas com tons de pele mais escuros, o que produz e reproduz sofrimentos. São ainda resquícios dos processos de subjetivação do racismo pela busca do embranquecimento, o que não foi uma escolha do negro, e sim uma imposição estatal, assimilada avidamente por uma sociedade brancocêntrica, racista e escravagista. (MAIA, 2018, p. 280).

Apesar de comprovadamente equivocados e ultrapassados, o resgate histórico da política do branqueamento (ou do embranquecimento) é importante para entender o panorama do contexto atual que carrega marcas dessa formação histórica e implica em um posicionamento dos educadores ao tratar da temática no ambiente escolar. A categoria raça foi social e historicamente construída a partir dessa relação assimétrica, o que resulta no racismo não apenas na individualidade do sujeito, mas na estrutura social, econômica, histórica e cultural brasileira (baseado na pretensa superioridade dos brancos).

Além disso, a estrutura de classes sociais no Brasil constitui-se a partir da ideia de raça, pois no período pós-abolição a população negra foi colocada à margem da sociedade, sem quaisquer oportunidades e ainda perseguida por um Código Penal criado para isso (lembremo-nos da lei da vadiagem, penalização da capoeira ou curandeirismo, por exemplo). Assim, enquanto descendentes de brancos herdavam terras e havia a transferência de renda entre gerações, a população descendente de negros ex-escravizados não possuía a mesma oportunidade.

Em suma, é pacífico o entendimento de que raça humana não é um conceito fixo, natural ou biológico, mas que carrega grande significado e importância ao discutir aspectos culturais e sociais da sociedade. Assim, o branco precisa ser colocado em questão por ser um lugar de vantagem nesta sociedade fundada sob o racismo, que se manifesta estruturalmente, institucionalmente e individualmente.

\section{BRANQUITUDE EM FOCO: um estudo a partir do opressor}

"A modernidade abordou a diversidade de duas formas básicas: assimilando tudo que é diferente a padrões unitários ou 'segregando-o' em categorias fora da 'normalidade' dominante" (GIMENO SACRISTÁN, 2001, p. 124). A partir dessa citação, mobilizo algumas provocações que podem servir como ponto de partida para a reflexão que iremos propor: Por que grande parte dos estudos aborda os oprimidos e não o opressor como ponto de partida no estudo das relações raciais? Por que o "padrão" ainda é visto como o 
branco, sendo que o Brasil é a segunda maior população com ascendência negra ${ }^{6}$ ? São perguntas que geram discussões e nos levam ao estudo crítico dos processos históricos de construção do termo raça e sua consequente hierarquização. A colonialidade aos quais estamos submetidos é tão forte que somos direcionados a pensar o diferente a partir do branco. Nesse sentido, Grada Kilomba afirma que é importante marcar:

E o que quer dizer marcar? Quer dizer também falar sobre diferenças. Por exemplo, como pessoas negras, muitas vezes, somos referidos como diferentes. E eu coloco a questão: diferente de quem? Quem é diferente? Tu és diferente de mim ou eu sou de ti? Para dizer a verdade, somos reciprocamente diferentes. Então a diferença vem de onde? Eu só me torno diferente se a pessoa branca se vê como ponto de referência, como a norma da qual difiro. Quando me coloco como a norma, aí os outros se tornam diferentes de mim. Então é preciso desconstruir o que é diferença. (KILOMBA, 2016, p. 4).

Os Estados Unidos, com os critical whiteness studies, são a principal fonte e os precursores sobre o estudo da branquitude. Observamos que os estudos sobre a branquitude passaram por três ondas nos EUA: a primeira de denúncia do privilégio da branquitude; a segunda que consistiu em brancos escrevendo sobre suas subjetividades novamente o branco como centro; e a terceira e atual que se configura por pensar a branquitude enquanto lugar de poder na estrutura racializada, questionando a supremacia branca (poder nas mãos de pessoas brancas).

Destacamos que Frantz Fanon, pensador caribenho e africano, em Pele Negra, Máscaras Brancas (1952) já defendia o argumento de abolição da raça para libertar o branco de sua branquitude e o negro de sua negritude. Segundo o autor, a identidade racial é um encarceramento que impede o homem de gozar da sua condição humana. Steve Biko (1978) também propôs importantes questões sobre a temática, ao lutar contra o racismo estrutural sul-africano. $\mathrm{O}$ autor traz a dificuldade de definição, ou autodefinição, entre a classificação de raça e cor:

[...] Juiz Boshoff: Mas então por que vocês se referem a si mesmos como "negros"? Por que não pessoas "marrons"? Quero dizer que vocês são mais marrons do que negros.

Biko: Do mesmo modo como eu acho que as pessoas brancas são mais cor-de-rosa, e amarelas ou pálidas do que brancas. [...] (Biko, 1990, [1978], p. 129).

\footnotetext{
${ }^{6}$ Segundo Carvalho (2001, p. 9), somos a nação com a segunda maior população com ascendência negra do mundo, sendo a Nigéria a primeira.
} 
Assim, com base na reflexão acima, propomos um deslocamento do olhar para a análise da branquitude no Brasil. A branquitude tornou-se tema emergente no Brasil, pois, em geral, a teoria antirracista brasileira investiga os oprimidos (negros e indígenas) e não o opressor (branco), “desta forma, é sugerido que a opressão é somente um 'problema do oprimido’ em que o opressor não se encontra relacionado" (CARDOSO, 2010, p. 610). Assim, o deslocamento do olhar para problematizar o lugar do branco em uma relação de desigualdade racial pode trazer estratégias para o estudo do racismo a nível individual e estrutural, sem, obviamente, menosprezar a importância de pesquisas sobre negros e indígenas. A ideia desses estudos é preencher as lacunas nas teorias das relações raciais no Brasil, desconstruir os privilégios que acompanham a branquitude e os seus mecanismos de perpetuação. Não se configura e nem pretende ser um ataque a indivíduos brancos, tampouco há o intuito de colocá-los novamente no palco, mas discutir os privilégios raciais desse grupo, partindo da busca por entender como a cor tornou-se fator determinante no Brasil para quem poderia votar, frequentar certos ambientes, ter acesso à educação, aos cuidados com a saúde etc. e como isso ainda afeta e estrutura a sociedade atual.

A identidade racial branca, assim como todas as outras, é diversa e modifica-se ao longo do tempo. No entanto, entendemos que "a branquitude é um lugar de privilégios simbólicos, subjetivos, objetivo, isto é, materiais palpáveis que colaboram para a construção social e reprodução do preconceito racial, discriminação racial 'injusta' e racismo" (CARDOSO, 2010, p. 611). Destacamos que o branco nesse contexto é uma construção cultural, social e política, assim o conceito de branquitude não é um fenômeno individual.

Em suma, a branquitude procura se resguardar numa pretensa ideia de invisibilidade, ao agir assim, ser branco é considerado como padrão normativo único. O branco enquanto indivíduo ou grupo concebido como único padrão sinônimo de ser humano "ideal" é indubitavelmente uma das características marcantes da branquitude em nossa sociedade e em outras (Rachleff, 2004, p. 109; McLaren, 2000, p. 263; Roediger, 2000, p. 1-17 apud CARDOSO, 2010, p. 611).

Apesar das configurações brasileiras serem bastante diferentes da americana quanto à (auto)declaração racial, pois há no Brasil um grande colorismo, sendo que alguns estudiosos chegam a afirmar que não há brancos no país devido à miscigenação, os 
processos de racialização brasileiros, em geral, referem-se à cor e tonalidade da pele. Nesse sentido, de acordo com Cardoso (2010), lembremo-nos do artigo de Guerreiro Ramos (1957) ${ }^{7}$, A patologia social do 'branco' brasileiro, que iniciou as publicações sobre a branquitude no Brasil. Nele o autor afirma que a patologia do "branco brasileiro" é que, apesar de a maioria ter ascendência miscigenada cultural e biológica com os negros e indígenas, a identidade é negada pelos brancos apenas pela cor da pele ser clara (por isso o termo branco entre aspas). É comum, por exemplo, vermos pessoas falarem de avós italianos ou alemães com orgulho, enquanto menosprezam suas origens indígenas ou africanas.

Ramos foi o precursor no Brasil a deslocar olhar das margens para o centro. Esse movimento proposto por ele e por outros estudiosos ${ }^{8}$ tem o objetivo de denunciar o conteúdo da branquitude, que até então permanecia ilesa de uma análise crítica. Deslocar o olhar é importante, pois, segundo Richard Dyer (1988), estudos que focam apenas nas minorias contribuem para a ideia de que elas estão fora da norma - e não de que a ideia de norma deveria ser discutida:

Olhar com tamanha paixão e unicidade de propósito para os grupos não dominantes teve o efeito de reproduzir o sentimento de estranheza, diferença e excepcionalidades desses grupos, o sentimento de que eles constituem desvios da norma. Entrementes, a norma seguiu adiante, como se fosse a maneira natural, inevitável e comum de sermos humanos. (DYER, 1988, p. 44).

Assim, independente da abordagem utilizada pelo professor em sala de aula, sobre as quais trataremos no tópico seguinte, é preciso compreender que apesar do discurso de que o Brasil se constitui pela singularidade de ser um país miscigenado, ao contrário da imagem amistosa politicamente construída e vendida internacionalmente, oprime e discrimina grupos indígenas e afrodescendentes. Nesse sentido, deslocar a questão do opressor para o centro do debate preenche lacunas importantes quanto à desmistificação da histórica branca e convoca um grupo que insiste em desresponsabilizar-se por suas ações ao longo dos séculos.

\footnotetext{
${ }^{7}$ Cardoso (2010) mostra que Guerreiro Ramos foi um dos precursores ao discutir a "patologia branca no Brasil" utilizando o termo brancura (que corresponderia hoje à branquitude). No entanto, o termo branquitude foi utilizado pela primeira vez no Brasil por Gilberto Freyre (1962), que criticava tanto o uso de branquitude como negritude devido à miscigenação.

${ }^{8}$ Após Ramos (1957), Edith Piza aprofundou os estudos sobre a branquitude brasileira com os artigos "Branco no Brasil? Ninguém sabe, ninguém viu" (2000) e "Porta de Vidro: entrada para a branquitude" (2002) seguida por outros autores apontados por Cardoso (2010).
} 


\section{DIÁLOGOS SOBRE INTERCULTURALIDADES E BRANQUITUDES}

A nossa formação histórica está marcada pela eliminação física do "outro" ou por sua escravizacão, que também é uma forma violenta de negação de sua alteridade. (CANDAU, 2002, p. 126).

Vivemos em sociedades multiculturais e essa forma de vida reverbera no cotidiano escolar e por isso deve ser problematizada na educação escolar. No entanto, como afirma Candau (2005), “o que parece consensual é a necessidade de se reinventar a educação escolar”. Nesse sentido, discutiremos a questão da educação escolar a partir do desafio de abordar as diferenças em sala de aula, fazendo um breve regate dos conceitos de multiculturalismos, branquitudes e branquidade, e, por fim, discutindo a importância dos estudos sobre a branquitude a partir da interculturalidade crítica.

Inicialmente, é importante destacar que o termo branquitude pode dividir-se em crítica e acrítica, "A branquitude crítica refere-se ao indivíduo ou grupo branco que desaprovam publicamente o racismo. Enquanto a branquitude acrítica refere-se à branquitude individual ou coletiva que sustenta o argumento em prol da superioridade branca" (CARDOSO, 2010b, p. 46). Já o termo branquidade começou a ser utilizado a partir de 2004, com a publicação de Vron Ware Branquidade: identidade branca e multiculturalismo. Apesar de o termo branquidade ser diferente de branquitude, segundo Jesus (2012), a mudança é apenas de nomenclatura. Aqui reside o cuidado na utilização do termo: entendendo que sempre houve grande divergência de pensamento entre brancos, desde o século XIX. A violência está em um projeto político dominante em que a escola sempre teve grande parcela de culpa por reproduzir padrões coloniais. Podemos dizer que ser racista é uma construção educativa (estrutural, institucional e não somente individual) e não uma marca de nascença.

O tema é desafiador, mas também inspirador, pois mostra relevantes apontamentos para a abordagem da temática racial em sala de aula, contrária à negritude apenas como objeto de estudo, e buscando compreender o conceito ficcional de raça. Assim, "Os estudos da branquidade se inserem na polêmica multicultural ao traçar a história econômica e política da invenção da 'cor branca', objetivando atacar os privilégios que a acompanham e analisar as práticas culturais que a criaram e a perpetuam" (LIRA, 2005, p. 234). 
Não há educação que não esteja dentro de processos socioculturais, por este motivo é necessário discutir constantemente como esses processos são abordados no contexto educacional, sob o risco de reproduzir padrões coloniais e desconsiderar as demandas da atualidade. Candau (2008, p. 14) propõe alguns questionamentos interessantes: “[...] o que há de novo na maneira contemporânea de conceber essas relações? Por que se fala e se discute tão acaloradamente hoje sobre as relações entre educação e cultura(s)? Que especificidade esta problemática tem na atualidade?”.

Hoje esta consciência do caráter homogeneizador e monocultural da escola é cada vez mais forte, assim como a consciência da necessidade de romper com esta e construir práticas educativas em que a questão da diferença e do multiculturalismo se façam cada vez mais presentes. (CANDAU, 2008, p. 15)

Nesse sentido, para aproximar-se dos universos simbólicos dos estudantes, a escola precisa incorporar as questões culturais de forma crítica ao trabalho realizado em sala de aula. Diante de diversas abordagens teórico-metodológicas, surge o desafio de decidir qual delas atenderá de fato às demandas dos estudantes e da sociedade. Como afirma Paulo Freire (1967, p. 68), "necessitávamos de uma educação para a decisão, para a responsabilidade social e política". Não propomos uma solução para a questão do distanciamento entre a escola e as diferentes culturas, mas uma reflexão acerca das possibilidades existentes para a abordagem da temática na educação, levando em consideração que "[...] a educação teria de ser, acima de tudo, uma tentativa constante de mudança de atitude" (FREIRE, 1967, p. 94). A busca por essa educação libertadora, emancipadora e crítica leva-nos à reflexão de que:

Ditamos ideias. Não trocamos ideias. Discursamos aulas. Não debatemos ou discutimos temas. Trabalhamos sobre o educando. Não trabalhamos com ele. Impomos-lhe uma ordem a que ele não adere, mas se acomoda. Não lhe propiciamos meios para pensar o autêntico, porque recebendo as fórmulas que lhe damos, simplesmente as guarda. Não as incorpora porque a incorporação é o resultado de busca de algo que exige, de quem o tenta, esforço de recriação e de procura. Exige reinvenção. (FREIRE, 1967, p. 97).

Assim como a interculturalidade, o multiculturalismo não nasceu no ambiente acadêmico. São demandas da sociedade que advém, principalmente, da luta dos grupos sociais discriminados e excluídos. Como afirma Candau (2004), inúmeras são as concepções e vertentes do multiculturalismo (conservador, liberal, celebratório, crítico, 
emancipador, revolucionário, entre outros). No entanto, a autora afirma que as duas abordagens principais são a descritiva, como características das sociedades atuais, e a propositiva, que o entende como uma "maneira de atuar, de intervir, de transformar a dinâmica social” (p. 20). Nosso foco será essa última abordagem, porém dentro dela também há subdivisões (assimilacionista, diferencialista e interativo). O multiculturalismo interativo, também denominado interculturalidade, é o que nos interessa no momento.

Candau (2004, p. 22) elenca as principais características da interculturalidade: 1) promoção da inter-relação entre os diferentes grupos culturais; 2) visualização das culturas como um processo contínuo de construção e reconstrução, algo dinâmico; 3) compreensão de que a hibridização cultural é intensa, portanto, as culturas não são puras; 4) a consciência dos mecanismos de poder que permeiam as relações culturais. E destaca que:

As relações culturais não são relações idílicas, não são relações
românticas, elas estão construídas na histórica e, portanto, estão
atravessadas por questões de poder, por relações fortemente
hierarquizadas, marcadas pelo preconceito e discriminação de
determinados grupos. (CANDAU, 2003, p. 23).

Nesse sentido, ao propormos o debate das questões raciais em sala de aula com enfoque também na branquitude, entendemos que essas relações culturais (e raciais) serão discutidas e problematizadas, buscando justamente colocar os holofotes sobre as questões de poder que hierarquizaram inclusive os modos de pesquisar e de se fazer ciência a partir do "outro" (não branco) e que, portanto, normaliza novamente o branco como "padrão". Assim, entender a branquitude brasileira e seus processos de transformação ao longo do tempo consiste em um passo importante para a desconstrução de visões que consideram o problema do racismo e das desigualdades brasileiras como "problemas dos outros", isentando o branco da luta que é de todos. Desta forma, discutimos também a questão da colonialidade do poder e colonialidade do saber. Inicialmente, destacamos que há uma grande diferença entre colonialismo e colonialidade, pois:

O colonialismo denota uma relação política e econômica, na qual a soberania de um povo está no poder de outro povo ou nação, o que constitui a referida nação em um império. Diferente desta idéia, a colonialidade se refere a um padrão de poder que emergiu como resultado do colonialismo moderno, mas em vez de estar limitado a uma relação formal de poder entre dois povos ou nações, se relaciona à 
forma como o trabalho, o conhecimento, a autoridade e as relações intersubjetivas se articulam entre si através do mercado capitalista mundial e da idéia de raça. Assim, apesar do colonialismo preceder a colonialidade, a colonialidade sobrevive ao colonialismo. Ela se mantém viva em textos didáticos, nos critérios para o bom trabalho acadêmico, na cultura, no sentido comum, na auto-imagem dos povos, nas aspirações dos sujeitos e em muitos outros aspectos de nossa experiência moderna. Neste sentido, respiramos a colonialidade na modernidade cotidianamente. (MALDONADO-TORRES, 2007, p. 131).

De acordo com Catherine Walsh (2009, p. 14), a colonialidade do poder estabeleceu e fixou uma hierarquia racializada que apaga as ricas diferenças históricas, culturais e linguísticas e coloca indígenas e negros como identidades negativas. Por este motivo, realizamos neste artigo um breve resgate histórico sobre a política do branqueamento brasileiro e o Congresso Internacional das Raças, visando ilustrar como se deu parte desse processo que marca a desumanização dos sujeitos. Walsh (2009) destaca ainda que o eurocentrismo constituiu-se por meio da colonialidade do poder como concepção hegemônica, o que ela denomina de colonialidade do saber.

A ausência de estudos sobre a branquitude no Brasil até pouco tempo também pode ser entendida como um reflexo da colonialidade, pois o enfoque dificilmente será o que é considerado padrão, hegemônico. Por isso, ao abordar a temática racial em sala de aula, questionar as bases fundantes do que se considera "padrão" e sua construção ao longo da história, além dos mecanismos de dominação e privilégios da branquitude pode ser uma excelente estratégia contra o racismo, pois dá um novo sentido ao diferente, pois as diferenças se constituem a partir de algo ou alguém (relações de poder). Catherine Walsh (2001, p. 10-11) entende a interculturalidade como:

Um processo dinâmico e permanente de relação, comunicação e aprendizagem entre culturas em condições de respeito, legitimidade mútua, simetria e igualdade.

Um intercâmbio que se constrói entre pessoas, conhecimento, saberes e práticas culturalmente diferentes, buscando desenvolver um novo sentido entre elas na sua diferença.

Um espaço de negociação e de tradução onde as desigualdades sociais, econômicas e políticas, e as relações e os conflitos de poder na sociedade não são mantidos ocultos e sim reconhecidos e confrontados.

Uma tarefa social e política que interpela ao conjunto da sociedade, que parte de práticas e ações sociais concretas e conscientes e tenta criar modos de responsabilidade e solidariedade.

Uma meta a alcançar. (WALSH, 2001, p. 10-11 apud CANDAU, 2004, p. 23-24, grifo nosso). 
Com base no trecho acima, podemos dizer que o que norteará o trabalho sobre a branquitude em sala de aula de acordo com a interculturalidade crítica será o reconhecimento das relações de poder para que se possa confrontá-las e criar modos de responsabilidade e solidariedade. Entendemos, assim como Walsh (2005, p. 25), que é preciso reconstruir o pensamento crítico a partir de outro modo, um modo que não considere o não branco como diferente, um modo que não esteja embebido pelo colonialismo que fundou o Brasil e se manifesta hoje por meio da colonialidade, um modo não de dominação, mas de equidade e respeito às diferenças que tanto enriquecem a sociedade e o ambiente escolar, mas que são pouco exploradas pela escola. Assim, a interculturalidade, como afirma a autora, realmente é uma meta a se alcançar.

\section{CONSIDERAÇÕES FINAIS}

Discutir a branquitude ao longo da história e sua contribuição para a constituição e manutenção do atual cenário brasileiro tem o objetivo de deslegitimar o status conferido à branquitude através da hierarquização racial, desumanizando o que é considerado fora do padrão imposto por quem detinha o poder. Entendemos que o estudo dos efeitos da branquitude no ambiente escolar pode contribuir para enriquecer o debate racial, além de questionar e desconstruir a história branca, masculina, eurocêntrica e dominadora que fundou o Brasil e resultou nas desigualdades contra as quais lutamos.

Com base no recorte do texto, compreendemos que não há um multiculturalismo, mas multiculturalismos. Neles, a diversidade geralmente é vista como algo unitário, sob uma ótica individualista que não se relaciona com o todo. Por este motivo, defendemos a interculturalidade como possibilidade para mobilizar estudos sobre a branquitude na medida em que o diverso não significa muito sem considerar as inter-relações e trocas, tanto as políticas quanto as aprendizagens que podemos ter com as diferenças.

A interculturalidade crítica na educação tem afinidade com o estudo sobre a branquitude brasileira por envolver a luta contra a opressão e a discriminação as quais grupos minoritários são submetidos ao longo da história por grupos poderosos e privilegiados. Desta forma, compreendemos que não basta estudar ou discutir os grupos oprimidos, mas também enfocar os grupos poderosos e privilegiados e seus mecanismos de poder e privilégio ao longo da história. 
Evidenciar a história econômica, política e cultural da invenção das raças humanas e do branco como "padrão" tem o objetivo de atacar os privilégios que acompanham a branquitude e compreender as práticas culturais que perpetuam na sociedade brasileira e servem aos estereótipos e mecanismos de discriminação racial. Devemos, assim, questionar cada linha dessa história que funda o Brasil e suas desigualdades: uma história escrita por homens brancos e carregada de silenciamento e violência. A temática é desafiadora, pois está na contramão do que geralmente é realizado na educação brasileira, mas os precursores abriram caminhos e trouxeram importantes conceitos que podem contribuir para a abordagem da questão racial em sala de aula, com foco na branquitude e seus privilégios, e buscando compreender o conceito ficcional de raça.

A branquitude nas relações raciais vem ganhando destaque nos estudos acadêmicos no Brasil, o que aponta para a necessidade de aprofundamento e de ampliação da discussão visando preencher as lacunas históricas e teóricas. Trouxemos essa contribuição ao problematizar a discussão sobre a branquitude brasileira na educação, deslocando o olhar das margens para o centro (do oprimido para o opressor, da negritude para a branquitude) com base na interculturalidade crítica, mas deixamos questões em aberto por entender que há muito a ser estudado e debatido dentro e fora do ambiente escolar...

\section{REFERÊNCIAS}

BIKO, S. Escrevo o que eu quero. Série Temas, vol. 21. Sociedade e Política. Trad. Grupo Solidário São Domingos. São Paulo: Ática, 1990 [1978].

CANDAU, V. M. Sociedade, Cotidiano Escolar e Cultura(s): uma aproximação.

Educação \& Sociedade, ano XXIII, n 79 , agosto, 2002, p. 125-161.

CANDAU, V. M. Reinventar a escola. 4 ed. Petrópolis: Vozes, 2005.

CANDAU, V. M.; MOREIRA, A. F. (orgs). Multiculturalismo: Diferenças Culturais e Práticas Pedagógicas. 2 ed. Rio de Janeiro: Petrópolis. Vozes, 2008.

CARDOSO, L. Branquitude acrítica e crítica: a supremacia racial e o branco antiracista. Revista Latinoamericana de Ciencias Socialez, Niñes y Juventud. Vol. 8. n. 1, p. 607-630, jan-jun, 2010.

CARDOSO, L. Retrato do branco racista e anti-racista. Reflexão e Ação, v. 18, n. 1, p. 46-76, jan-jun 2010b. Disponível em:

https://www.researchgate.net/publication/228690860_RETRATO_DO_BRANCO_RA CISTA_E_ANTI-RACISTA. Acesso em 06 de fev. de 2021. 
CARVALHO, J. J.; SEGATO, R. L. Uma proposta de cotas e ouvidoria para a Universidade de Brasília. Brasília, 2001. [Manuscrito].

DYER, R. White. London and New York: Routledge, 1988.

FANON, F. Pele Negra. Máscaras Brancas. Tradução de Renato da Silveira. Salvador: EDUFBA, 2009.

FARIAS, K. S. C. dos Santos. Práticas mobilizadoras de cultura aritmética na formação de professores da Escola Normal da Província do Rio de Janeiro (18681889): ouvindo fantasmas imperiais. Tese (Doutorado em Educação) - Universidade Estadual de Campinas - Faculdade de Educação - Campinas, SP, 2014.

FREIRE, P. Educação como Prática de Liberdade. Rio de Janeiro: Paz e Terra, 1967.

GIMENO SACRISTÁN, J. Políticas de lá diversidade para uma educación democrática igualadora. In: SIPÃN COMPAÑE, A. (coord.). Educar para la diversidade em el siglo XXI. Zaragoza (Espanha): Mira, 2001.

JESUS, C. M. d. Branquitude x Branquidade: uma análise conceitual do ser branco. In: III Encontro Baiano de Estudos em Cultura. Cachoeira/Ba, 2012.

KILOMBA, G. (2016). "Descolonizando o conhecimento" Uma Palestra-Performance de Grada Kilomba. Tradução, Oliveira, J. São Paulo, Goethe-Institut.

LACERDA, J. B. de. Sur le métis au Brésil. In: Premier Congrès Universel des Races: 26-29 juillet 1911. Paris: Devouge, 1911.

LIRA, R. Resenha: Ware, Vron (org.). Branquidade: identidade branca e multiculturalismo. Rio de Janeiro: Garamond, 2004. In: Ilha do Desterro: A Journal of English Language, Literatures in English and Cultural Studies, núm. 48, enero-junio, 2005, pp. 234-238. Universidade Federal de Santa Catarina - Florianópolis, Brasil. Disponível em: https://www.redalyc.org/pdf/4783/478348686011.pdf. Acessado em 5 de out. 2021.

MAIA, K. S.; ZAMORA, M. H. N.. O Brasil e a lógica racial: do branqueamento à produção de subjetividade do racismo. Psicol. clin., Rio de Janeiro, v. 30, n. 2, p. 265286, 2018. Disponível em http://pepsic.bvsalud.org/scielo.php?script=sci_arttext\&pid=S010356652018000200005\&lng=pt\&nrm=iso.. Acessada em 15 jan. 2021. http://dx.doi.org/10.33208/PC1980-5438v0030n02A04.

MALDONADO-TORRES, N. Sobre la colonialidad del ser: contribuciones al desarrollo de un concepto. In: CASTRO-GÓMEZ, Santiago; GROSFOGUEL, Ramon (orgs.). El giro decolonial: Reflexiones para una diversidad epistémica más allá del capitalismo global. Bogotá: Universidad Javeriana-Instituto Pensar, Universidad Central-IESCO, Siglo del Hombre Editores, 2007. p. 127-167. 
MUSTAPHA, C. O islã e o Ocidente: um encontro com Jacques Derrida. Tradução Roberto Said. Belo Horizonte: Editora UFMG, 2013.

WALSH, C. Interculturalidade Crítica e Pedagogia Decolonial: In-Surgir, ReExistir e Re-Viver. Equador, 2009.

SCHUCMAN, L. V. Entre o "encardido", o "branco" e o "branquíssimo": raça, hierarquia e poder na construção da branquitude paulistana. Tese (Doutorado em Educação) - Universidade de São Paulo - Instituto de Psicologia - São Paulo, SP, 2012.

SCHWARCZ, L. M. Previsões são sempre traiçoeiras: João Baptista de Lacerda e seu Brasil branco. História, Ciências, Saúde - Manguinhos, Rio de Janeiro, v.18, n.1, jan.mar. 2011, p.225-242.

SOUZA, V. S. de; SANTOS, R. V. O Congresso Universal de Raças, Londres, 1911: contextos, temas e debates. Boletim do Museu Paraense Emílio Goeldi. Ciências Humanas, v. 7, n. 3, p. 745-760, set.-dez. 2012.

SPILLER, G. (Org.). Papers on inter-racial problems communicated to the First Universal Races Congress. Londres: P. S. King \& Son; Boston: The World's Peace Foundation, 1911.

WALSH, C. La educación intercultural em la educación. Peru: Ministerio de Educación, 2001.

\section{Recebido em: 15/09/2021}

Aprovado em: 10/10/2021 